\title{
Assessment of a dental rural teaching program
}

\author{
George Johnson'
}

Anthony Blinkhorn²

\begin{abstract}
Objective: To evaluate the effectiveness of a rural clinical placement on students' self-perceived clinical skills and work location choice post-graduation.

Methods: A one month rural placement program was introduced in 2008-2009 for $4^{\text {th }}$ year dental undergraduates. Student's views on the rural exercise were collected by pre and post self-completion questionnaires, which were distributed to rural placement students and to the students who did not participate in the placement. Information was collected on self-reported skill levels in various clinical techniques using Likert scales and future rural work intentions. Clinical supervisors and University Faculty Members opinions on the students clinical work were also collected via interviews.

Results: The mean age of the respondents was 27 years and the majority were female (57\%). All the placement students (volunteers) completed pre and post placement questionnaires and (67\%) of the non-placement students completed the pre questionnaire and (65\%) a post questionnaire. When the two groups were compared in terms of their Likert scores, there was a significantly $(P<.02)$ larger increase in skill level in the rural group. Clinical supervisors confirmed volunteers increased in confidence and ability in clinical skills post placement. The majority (96\%) of students who completed a placement reported that they were more likely to work in a rural environment after graduation.

Conclusions: The rural placement improved the self-perceived clinical skills of the volunteers and enhanced positive attitudes towards working in a rural location. (Eur J Dent 2012;6:235-243)
\end{abstract}

Key words: Clinical; dental placement; rural; undergraduates

\section{INTRODUCTION}

There is a shortage of dentists working in Australian rural locations. ${ }^{1,2}$ This problem will increase in severity as the cohort of dentists who qualified

1 Health Research and Project Coordinator, University of Sydney, Sydney, AUSTRALIA

2 NSW Health Chair Department, Population Oral Health, University of Sydney, Sydney, AUSTRALIA

- Corresponding author: George Johnson Population Oral Health, 1 Mons Road, Westmead, NSW 2145, AUSTRALIA

Tel: G.Johnson: +61288214365

Fax: +61288214366

Email: george.johnsondsydney.edu.au between 1965-1975 begin to retire, especially as many of them work in rural areas. It is essential to encourage new dental graduates to consider working in country areas to alleviate this problem.

Research literature in other health disciplines shows that a rural placement can increase rural recruitment. ${ }^{3,4,5}$ In 2005 the James Cook University School of Medicine in Northern Australia provided eight week rural internships for all $6^{\text {th }}$ year medical students. The internships were evaluated via questionnaires, site visits, interviews and follow up teleconferences, including a compulsory debrief 
session. The students reported that the internship was one of the most important clinical experiences of the final year course and they were able to meet their academic curriculum learning objectives. ${ }^{3}$ The study did not examine whether the students took up rural employment post-graduation and the researchers noted that the long term destination of the students would be an important aspect of further investigation. ${ }^{3}$

A longitudinal study of medical students in Western Australia identified rural background, self-reported value of the experience, placement duration and voluntary attendance at the rural placement as some of the factors which could persuade students to work in a rural practice. ${ }^{6} \mathrm{~A}$ study in 2007 also concluded rural background is a key predictor for working in a rural medical practice. ${ }^{7}$ Other studies add to the substantial evidence that having a rural background is the single most significant predictor of a subsequent rural career for medical practitioners. $8,9,10$ The timing of a rural placement is important, with a study showing that offering it to $3^{\text {rd }}$ year undergraduates instead of $4^{\text {th }}$ year students led to lower graduate recruitment into rural sectors. ${ }^{11}$ A rural placement program in Tasmania reported that it provided a positive influence on the students' intention to work rurally after their graduation. ${ }^{12}$

Despite these positive reports a review published in $2007^{13}$ claimed that there is still no definitive evidence of the effectiveness of rural internships and recommends isolating the factors which positively influence graduates working in rural regions by producing methodological, structured, rigorous, longitudinal studies which follow up graduates and control for the independent predictors of rural practice.

The evidence of the influence of rural placements on dental student's future plans is more limited. Nunn and Freeman ${ }^{14}$ highlighted that undergraduate teaching in many parts of the world is focused on techniques which are suited for developed populations and education is providing less encouragement for undergraduates to practice in remote areas. They felt a significant clinical outreach experience away from the large centralized teaching hospitals might encourage students to work in a rural location.

The main problem is how to implement this strategy. One example at the University of Western
Australia incorporated an optional Rural, Remote and Indigenous placement (RRIP). ${ }^{15}$ The program lasted from 2002-2005 with 143 students graduating in this period, $55 \%$ had a rural placement. There was a gradual increase in the proportion of students who had participated in the placement who then went on to work in a rural area within 12 months of graduation; $26 \%$ in 2002, $38 \%$ in 2003 , $60 \%$ in 2004 and $48 \%$ in 2005 . The majority (95\%) were very positive in their feedback and found the placements to be a valuable learning experience. ${ }^{15}$

Melbourne Dental School ${ }^{16}$ provided a 4 week rural outplacement in 2006-2007 for 70 students in groups of 6 to 10 to an outreach clinic in the small town of Shepparton and questionnaires provided feedback of their experience. The study found $19.5 \%$ of students were considering rural practice post placement with only one student uninterested and $79.1 \%$ expressed definite affirmation. All the students gained confidence in performing most procedures during their placement and it helped prepare them for dentistry post-graduation. Mascarenhas et al $^{17}$ stated that community based experiences are focussed on patient care and time management skills rather than learning specific clinical skills.

A placement program in South Australia showed that dental students can make a significant contribution to the provision of public dental services in rural communities, in terms of reducing patient waiting lists, providing patient care and giving students the opportunity to acquire an appreciation of the factors that influence rural dental healthcare practice. $^{18}$

A Community Based Dental Education Program set in the United States ${ }^{19}$ reported that students in community clinics see approximately 6 or more patients per day, whereas traditional dental school clinics which are focused on education see approximately 2 to 3 patients per day. The benefits for students from community programs were noted as the acquirement of knowledge, skills and values that are not readily available in Dental school based clinical training. They concluded that students care for more patients, gain teamwork skills and have the opportunity to treat a more diverse range of patients. ${ }^{19}$

An outreach scheme developed in the UK involved fourth year dental students seconded to primary care centers in socially deprived areas with 
inadequate general dental services and poor oral health. ${ }^{20}$ The students completed questionnaires prior to and after the program. Qualitative and quantitative research methodology was used in the program assessment using Likert scales and semi structured open questions. Post outreach the students reported an increase in confidence, improved time management skills and an enhanced ability to identify certain clinical problems. Although not a rural experience it did show that working in a primary care location was popular and improved clinical skills. ${ }^{20,21}$

The Faculty of Dentistry, University of Sydney decided to implement a rural placement program drawing on the positive experiences of the Universities of Western Australia, Melbourne and Manchester as part of a strategy to promote rural training funded by the Australian Department of Health and Ageing. This paper discusses the effectiveness of rural placements in dental undergraduate teaching in terms of the suitability of the clinical training provided, its effect on the students' clinical skills and confidence and whether the program influences students to consider rural work postgraduation.

\section{MATERIALS AND METHODS}

\section{Sample and procedures}

With the approval of the Ethics Review Committee (RPAH Zone) data reported here were collected from fourth 'final' year Bachelor of Dentistry (BDENT) undergraduates. The Rural Placement Program was offered as a voluntary option to all final year undergraduates $(n=80)$ and $40 \%(n=32)$ volunteered.

A placement lasted one month at one of three rural clinics, working under supervision four clinical days per week with one day allowed for study. There were four one month placements at Bowral (6 students per placement) and Bathurst and Orange (taking 2 students each.) Each placement site had a registered dentist acting as a clinical supervisor for the students who received a training course to learn the Faculty's teaching protocols. The students worked in pairs on the placement, one being the operator and the other the assistant, rotating these roles every half day. There were three clinical supervisors involved in the program and several faculty staff. A faculty staff member was on hand to respond to student queries and issues throughout the placements. Pre placement meetings were set up to brief the students on the type of clinical care they would practice and to answer any concerns. Accommodation, travel costs and an allowance was provided by the University. Pre placement information booklets and maps were provided to the students.

The students were asked to voluntarily complete a questionnaire which was designed to seek the students, thoughts and opinions on the Rural Placement program, obtaining feedback on all aspects from the supervisors, accommodation, clinical tasks, non-clinical tasks, the effect the program has had on them, Likert scales scores on the students self-perceived clinical confidence and interest in rural practice and why. This paper focuses on the quantitative clinical Likert data with some reference to the qualitative findings from the open questions relating to the students clinical work.

Three Clinical Supervisors, one from each rural clinic and three University of Sydney Faculty Members were interviewed as part of the evaluation and responses included in this paper pertain to the students' clinical work. The Clinical Supervisors were interviewed via phone and the Faculty members were interviewed in person.

Student respondents were separated into those who volunteered to participate (volunteers) and those who did not (non-volunteers). A self-administered pre and post placement questionnaire was distributed to volunteers and non-volunteers in person and via email, questions were a mixture of closed and semi-structured open questions. Likert scales were used to measure the students self reported clinical confidence and ability in five key skills, namely, Treatment planning, Time Management, Communication Skills, Clinical Ability and Treatment Skills. Students were asked to complete the questionnaires in an unsupervised environment.

Pre questionnaires were distributed to volunteers and non-volunteers two weeks prior to the first rural placement. A follow up questionnaire was given to the volunteers when they returned from their placement, and the non-volunteers follow up questionnaire was distributed at the end of the placement program. Non respondents were resent questionnaires via email and a follow up telephone call was made one week later to students who had still not responded. 


\section{RESULTS}

\section{Data Analysis}

The first part of the analysis provides a profile of the students' socio-demographic profile including their rural background. Data were entered into SAS 9.1 for frequency, mean, percentages and paired ttests were used to compare the various Likert scale group data. Open ended responses were analysed using framework analysis to identify trends and themes in the group responses.

All the volunteer students ( $n=32$ ) completed a pre-placement and post placement questionnaire whilst $67 \%$ of the non-volunteers ( $n=32$ ) completed a pre-questionnaire and $65 \%(n=20)$ of this group completed a post placement questionnaire. A post placement questionnaire was only offered to non-volunteers who completed the pre-placement questionnaire for comparison reasons.

All three Clinical Supervisors and three Faculty Members who were involved in the placement program were interviewed.

\section{Socio-demographic profile}

The mean age of the volunteers and non-volunteers was both 27 years and this is displayed in Table 1 along with the group's gender distribution.

Rural background has been broadly defined as any rural experience or rural exposure. ${ }^{12}$ Students were asked what type of environment they had grown-up in and to comment on any rural experience they had encountered.

Table 1 displays the rural background of the students. There was little difference between the volunteers and non-volunteers, with $38.7 \%$ in both groups having lived in a city environment. No one was raised in a very remote rural setting. There were more non-volunteers raised in small town areas $(8.1 \%)$ than the volunteers $(3.2 \%)$. However there is not enough difference between the two groups to confound the results and no significance difference between the groups when a paired t-test was performed with both groups predominantly from a city environment. ( $t=0.30 \mathrm{P}=.7686)$.

\section{Self-Analysis of the Students Clinical Skills} using Likert Scales

Table 2 shows the mean scores of the five clinical aspects for pre and post volunteers and non-volunteers using the Likert Scales. Based on a 5-point Likert scale where 5 is the highest possible selfperceived score, it can be seen that the mean scores for these five areas of clinical practice increased in the volunteer group, but generally remained static for those students who did not complete the Rural Placement. For example the volunteers reported an increase in the important areas of Treatment Planning of 3.4 to 3.8 , Communication skills 3.9 to 4.3 and Treatment skills 3.3 to 3.8 while the non-

Table 1. The mean age, gender and childhood/teenage locality of the volunteer and non-volunteer students.

\begin{tabular}{|c|c|c|c|c|c|c|c|}
\hline \multirow{3}{*}{ Mean Age } & & \multicolumn{2}{|c|}{ Volunteers } & \multicolumn{2}{|c|}{ Non Volunteers } & \multicolumn{2}{|c|}{ All } \\
\hline & & \multicolumn{2}{|c|}{27} & \multicolumn{2}{|c|}{27} & \multicolumn{2}{|c|}{27} \\
\hline & & $\mathrm{N}$ & $\%$ & $\mathrm{~N}$ & $\%$ & $\mathrm{~N}$ & $\%$ \\
\hline \multirow{3}{*}{ Gender } & Male & 13 & 40,6 & 15 & 45,5 & 28 & 43,1 \\
\hline & Female & 19 & 59,4 & 18 & 54,5 & 37 & 56,9 \\
\hline & Total & 32 & 100 & 33 & 100 & 65 & 100 \\
\hline \multicolumn{8}{|c|}{ Childhood Locality } \\
\hline Rural & & 2 & 3,2 & 5 & 8,1 & 7 & 11,3 \\
\hline Small Town & & 5 & 8,1 & 2 & 3,2 & 7 & 11,3 \\
\hline City & & 24 & 38,7 & 24 & 38,7 & 48 & 77,4 \\
\hline Total & & 31 & 50 & 31 & 50 & 62 & 100 \\
\hline
\end{tabular}

Table 2. The mean self-assessed dental skills of the volunteer and non-volunteer students as recorded by Likert Scales, prior to and after the Rural Placement.

\begin{tabular}{|c|c|c|c|c|c|c|c|c|c|c|}
\hline \multirow{2}{*}{ Students } & \multicolumn{2}{|c|}{ Treatment Planning } & \multicolumn{2}{|c|}{ Time Management } & \multicolumn{2}{|c|}{ Communication } & \multicolumn{2}{|c|}{ Clinical Ability } & \multicolumn{2}{|c|}{ Treatment Skills } \\
\hline & Mean & Std & Mean & Std & Mean & Std & Mean & Std & Mean & Std \\
\hline Pre Volunteer & 3,4 & 0,5 & 3,2 & 0,7 & 3,9 & 0,7 & 3,5 & 0,5 & 3,3 & 0,4 \\
\hline Post Volunteer & 3,8 & 0,3 & 3,6 & 0,6 & 4,3 & 0,4 & 3,8 & 0,5 & 3,8 & 0,4 \\
\hline Pre Non Volunteer & 3,6 & 0,4 & 3,5 & 0,6 & 4,3 & 0,5 & 3,6 & 0,6 & 3,5 & 0,6 \\
\hline Post Non Volunteer & 3,8 & 0,6 & 3,6 & 0,7 & 4,4 & 0,5 & 3,7 & 0,6 & 3,7 & 0,5 \\
\hline
\end{tabular}


volunteers increased less in their post placement scores with 3.6 to 3.8 for Treatment Planning, Communication 4.3 to 4.4 and Treatment skills 3.5 to 3.7 . The area the volunteer group perceived their greatest improvement was in Treatment skills with a 0.5 increase.

Table 3 presents the combined scores for the five different Likert skills, and shows that the post volunteers had almost the same mean score (19.3) as the post non-volunteers (19.2) despite the fact that the non-volunteers had a higher self-perceived score prior to the beginning of the Rural Placement program of 18.5 compared to a lower 17.3 from the volunteers. Displayed as a percentage the volunteer group shows an $8 \%(69.2 \%$ to $77.2 \%)$ increase in their combined self-reported skill level post placement, whereas the non-volunteers increase from pre to post placement was less than 3\% $174 \%$ to $76.8 \%)$.

A paired t-test showed a significantly higher mean skill score in the pre-placement non volunteers' scores compared to the pre placement volunteers ( $t=2.26 \mathrm{P}=<.05$ ), with a mean higher score of 1.2 (95\% Cl 0.1 to 2.2). The volunteer group reported a lower level of overall clinical ability compared with the pre-placement non-volunteers. Post placement responses show there was no significant difference between the two groups.

The volunteers and non-volunteers' changing scores from pre to post placement were compared to ascertain if there was a significant difference. Table 4 shows the paired t-test results and identified that the rural placement volunteers had a significantly greater increase in their mean combined clinical scores of 2.0 compared to 0.5 of the nonvolunteers $\left(t_{53}=2.35 ; P<.02\right)$. The mean difference is estimated at 1.5 with $95 \% \mathrm{Cl}$ between 0.2 to 2.7 .

\section{Clinical ISOH Scores}

The clinical treatment episodes undertaken by the students were entered into the NSW Dental Public Service data collection Information System for Oral Health (ISOH) and the main categories of care are shown in Table 5. Bowral having more students than Bathurst and Orange completed the most procedures. The most common clinical procedure in Bathurst was dental extractions, whilst at Bowral and Orange restorative care was the most common procedure, followed by acute care at Bowral and dental extractions at Orange. The

Table 3. The students mean Likert scale self-perceived scores for all five combined skill levels.

\begin{tabular}{lccc}
\hline Student Group & Mean & Std & Std Err \\
\hline Pre volunteers & 17,3 & 2,1 & 0,4 \\
Post Volunteers & 19,3 & 1,6 & 0,3 \\
Pre Non volunteers & 18,5 & 2,0 & 0,4 \\
Post Non volunteers & 19,2 & 2,0 & 0,4 \\
Total & 18,5 & 2,1 & 0,2 \\
\hline
\end{tabular}

Table 4. Comparison of within student change (post-pre) by volunteer status.

\begin{tabular}{|c|c|c|c|c|c|}
\hline Variable & Group & $\mathrm{N}$ & Mean & Std Dev & $95 \% \mathrm{Cl}$ \\
\hline Combination of all skills & Volunteers & 32 & 2 & 2,3 & 1.2 to 2.8 \\
\hline Combination of all skills & Non Volunteers & 23 & 0,5 & 2,3 & -0.5 to 1.5 \\
\hline Combination of all skills & Diff (1-2) & - & 1,5 & 2,3 & 0.2 to 2.7 \\
\hline \multicolumn{6}{|l|}{ T-Tests } \\
\hline Variable & Method & Variances & DF & t Value & $\operatorname{Pr}>|t|$ \\
\hline Combination of all 5 skills & Pooled & Equal & 53 & 2,35 & 0,0224 \\
\hline
\end{tabular}

Table 5. ISOH Data: Episodes of clinical care undertaken by Final Year Students in the Rural Placement Program.

\begin{tabular}{lcccccc}
\hline Clinic & $\begin{array}{c}\text { Treatment } \\
\text { Planning } \\
\text { and Prevention }\end{array}$ & $\begin{array}{c}\text { Periodontal } \\
\text { Care }\end{array}$ & Acute Care & $\begin{array}{c}\text { Dental } \\
\text { Extractions }\end{array}$ & $\begin{array}{c}\text { Restorative } \\
\text { Care }\end{array}$ & $\begin{array}{c}\text { Prosthodontics } \\
\text { and Denture } \\
\text { care }\end{array}$ \\
\hline Bathurst & 56 & 46 & 55 & 128 & 99 & 16 \\
Bowral & 80 & 89 & 405 & 250 & 460 & 11 \\
Orange & 24 & 8 & 40 & 42 & 50 & 18 \\
TOTAL & 160 & 143 & 500 & 420 & 712 & 182 \\
\hline
\end{tabular}


system recorded across all the placements a total of 712 episodes of restorative care, 500 episodes of acute care, 420 dental extractions, 160 treatment plans and prevention, 143 of periodontal care and 45 episodes of denture care and fixed prosthodontics. The mean number of episodes of care for each student across the three placements per placement was 59.

\section{Qualitative data on Clinical care}

This data was drawn from the semi-structured open questionnaire responses from students and interviews with the Clinical Supervisors and University Faculty Members.

\section{Student Open Question Responses on Rural} Clinical Experience

All the students were very pleased with the clinical education they received. Students noted increased clinical confidence and time management skills. Restorative care, diagnosis and extractions were the most commonly reported clinical procedures. Other procedures mentioned by several students were detecting caries, patient management, root canal therapy, acute care management, dealing with special care patients and cutting crown preparations. They reported that they were expected to complete patient treatment at a much faster pace than at the teaching metropolitan hospitals. According to the students they saw between 6 and 8 patients per day whereas at the University teaching hospitals non volunteers reported seeing approximately 3 to 4 patients per day. The non-volunteers reported completing more specialist dentistry such as prosthodontics and less basic clinical dentistry.

Non volunteers gave reasons for regretting not participating in the placement such as missing a valuable clinical experience, the opportunity to make new friends and making professional contacts. The minority of non-volunteers who had no regrets explained they felt being at the University teaching hospitals provided greater opportunity for more specialized clinical training such as fixed prosthodontics.

\section{Clinical Supervisor Responses}

The Clinical Supervisors reported the students increased in confidence, as well as improved clinical ability and clinical efficiency. Supervisors also commented that students improved in their treatment planning, time managements and communication skills. They also confirmed the students saw between 6-8 patients per day as their clinical efficiency improved.

\section{Faculty Members Responses}

They commented the pre-placement volunteers' were as clinically competent as the non-volunteers and many of the more capable students volunteered for the program. The Faculty Members noted some of the returning students had stronger communication skills and confidence based on debriefing conversations. Some students enquired about rural clinical employment at the rural clinics for post-graduation and almost all the students were very positive towards potentially working in a rural environment.

\section{Students Rural Intentions}

Table 6 displays the students reported interest in working in a rural location pre placement from two groups, $54.8 \%$ of the pre-placement volunteers were considering working in a rural placement after graduation compared to $35.5 \%$ of the non-volunteers.

Table 6 also shows that $96.9 \%$ of the volunteers post placement would consider working in a rural location after they graduate, a $42 \%$ increase in favor of working rurally. The non-volunteers were not asked this question in the follow up questionnaire as they had not had a rural experience to alter their perspective.

All of the volunteer students said they would recommend the placement to future students. The non-volunteer group was asked if they regretted

Table 6. The responses from volunteer and non-volunteer students related to working in a rural setting after their graduation.

\begin{tabular}{|c|c|c|c|c|c|c|c|}
\hline \multirow{2}{*}{ Students } & \multicolumn{2}{|c|}{ Yes } & \multicolumn{2}{|c|}{ No } & \multicolumn{2}{|c|}{ Undecided } & \multirow{2}{*}{$\begin{array}{c}\text { Total } \\
\text { n }\end{array}$} \\
\hline & $\mathrm{n}$ & $\%$ & $\mathrm{n}$ & $\%$ & $\mathrm{n}$ & $\%$ & \\
\hline Pre Volunteers & 17 & 54,8 & 0 & 0 & 14 & 45,2 & 31 \\
\hline Pre Non Volunteers & 11 & 35,5 & 9 & 29 & 11 & 35,5 & 31 \\
\hline Post Placement & 31 & 96,9 & 1 & 3,1 & 0 & 0 & 31 \\
\hline
\end{tabular}

Missing frequency $=2$ (one non responder from the volunteer group and one from the non volunteer group.) 
not taking part in the rural placement after hearing reports from the returning volunteers and $57 \%$ of them regretted not participating, 30\% were undecided and $13 \%$ had no regrets.

\section{DISCUSSION}

The overall response rate from the students was excellent, with all the volunteers and a high percentage of the non-volunteers (pre Questionnaire - $67 \%$ and post - 65\%) completing the pre and post placement questionnaires. Non respondents were followed up using email and mobile phones, with a mixture of phoning and SMS texting to encourage them to complete the questionnaire. The use of a control group increased the validity of the findings and by recording information pre and post completion of the Rural Placements. The program targeted $4^{\text {th }}$ year students ${ }^{11}$ and each placement lasted one month because the research concluded that this timeframe encouraged students to consider rural work post-graduation. ${ }^{6}$

Rural background was measured as the literature identified it as a potential confounder.6,7,8,9,10 The two student groups were found to be not significantly different in terms of their rural background allowing for comparisons to be made.

Likert scale methods and some open ended semi structured questions were used to provide both quantitative and qualitative data as the literature review showed these methods are a valuable research tool.3,4,15,20 Also Clinical Supervisors via phone interviews were asked semi structured questions regarding the clinical work completed to verify the student responses and ISOH data. The data collection system allowed a large amount of data to be acquired in a short time.

The Likert scales and students self-perceived levels of treatment planning, time management, communication skills, clinical ability and treatment skills were all positive for the rural sample. Our results are similar to the Manchester ${ }^{20}$ and Leeds studies ${ }^{21}$ which found that students increased in their confidence, time management and diagnosis skills. We also found that their selfperceived clinical skills increased, the students saw more patients per day in the rural clinic than at the dental school clinics and this was confirmed by the rural Clinical Supervisors. This supports the evidence by Baiit ${ }^{19}$ which also found students saw approximately 6 patients per day in a commu- nity clinic compared to 2 and 3 at the Dental school teaching clinics.

The non-volunteers had a significantly higher mean pre-placement score (18.5) than the volunteers (17.3). An explanation as to why the pre volunteers had a lower Likert score across the five skills could be due to pre placement anxiety. The finding that greater improvement occurs in the volunteers from pre to post placement than the non-volunteers is important as it demonstrates the significant increase in clinical confidence of the volunteer students post placement.

The volunteer and non-volunteer group were directly compared and there was a significantly $(P<.05)$ larger increase in skill level from pre to post placement for the volunteers than the nonvolunteers despite starting with a lower pre placement self-perceived score. This increase may be due to the volunteers' considerable clinical work undertaken whilst on the placement in seeing more patients per day and completing more basic clinical dentistry than at the metropolitan teaching hospitals. The supervisors commented that the students helped reduce the patient waiting lists at the Orange and Bathurst clinics supporting Richards et al ${ }^{18}$ who felt that dental students can make a significant contribution to the public dental services waiting lists.

The clinical data entered into the NSW Information System for Oral Health (ISOH) supports the reported responses from the students about their level of clinical activity, and is an independent verification that considerable practical primary care dentistry was undertaken.

In our study $97 \%$ of the volunteers post placement felt they were more likely to work in a rural setting after graduation, demonstrating a dramatic change in attitude which supports the findings of Western Australia ${ }^{15}$ and Melbourne ${ }^{16}$ who found students were encouraged to work rurally post placement. This shows the positive influence the rural placements had on the students' attitude towards considering working in a rural location upon graduation. Longitudinal follow up is important for monitoring the long term value of rural placements; therefore a follow up of these students will be undertaken in 18 months time to record their working location.

After the students returned from the rural placement, the non-volunteers were asked if they 
had any regrets based on what they had heard from the volunteers, more than half of the non-volunteers felt they had missed out on a valuable teaching experience and the chance to make and build contacts and friendships. This demonstrates the positive feedback from the volunteers post placement regarding the placement when reintegrated with the non-volunteers.

\section{Limitations}

Self-Report was used so there is potential for recall bias, judgement error, memory loss and providing socially desirable answers. However with this type of study self-report is probably the most practical way to collect data given the intensity of the dental undergraduates' curriculum. The weakness with semi-structured questions and Likert scales is that the students were somewhat restricted as they were asked a set of specific questions. An interview for each participant would have provided more detailed in depth responses, however this would have been very time consuming and labour intensive for both the student and interviewer. Likert scale scores are open to some interpretation and there was a higher response rate from the volunteer group and this may have had some impact.

The timing of the completion of questionnaires varied and this is a potential weakness, pre volunteers completed their questionnaire one week pre placement and within 14 days post placement. Non volunteers completed their pre placement questionnaires prior to the first placement and post placement they completed their questionnaires at the end of the teaching year. This had to be the case as the volunteers needed to be questioned soon after their placement to avoid memory loss and the non-volunteers responses were dependant on interactions with the returning volunteers, hence had to be undertaken after the final rural placement. By asking the non-volunteers at the end of the final year after all their clinical training, you would expect a positive shift in their perceived clinical scores and hence the groups' final mean clinical score would be expected to be higher not lower than if taken earlier in the year.

The questions were based on the questionnaire design and placement evaluation set up by the Manchester ${ }^{20}$ study, however the questionnaire was not a validated instrument and hadn't been used previously. The multiple sources of information gathering using student, faculty and clinician views on the students' clinical work provided consistent data ${ }^{22}$ which increases the validity and reliability of the findings. This paper has focussed on the quantitative data from the students' perspective of the rural placement program with relevant comments on the clinical training from faculty staff and clinical supervisors.

\section{CONCLUSIONS}

The rural placement program provided an excellent clinical experience as students reported that their clinical confidence and skills had improved. They also reported an increased likelihood to consider working in a rural location after graduation.

\section{ACKNOWLEDGEMENTS}

The placement program would not have been possible without the support of Associate Professor Sameer Bhole (South Western Sydney Local Health Network) and Ms Jennifer Floyd (Western Sydney Local Health Network). Dr Sally Clark, Dr Thomas Hasson and Dr Narayan Prasad were the clinical supervisors and their hard work and support along with their staff in the Local Health Networks were vital for the success of the program. Professors Chris Peck and Elizabeth Martin ensured the program received Faculty support and Ms Antonia Scorciapino was a valuable advisor when managing the budget. Ms Ramona Grimm, Department of Population Oral Health, made an important contribution to the project's running. Professor Blinkhorn's position is funded by the Centre for Oral Health Strategy, New South Wales Health and he thanks Chief Dental Officer Dr Wright and his staff for their help and guidance with the project. The rural placement program is funded by the Australian Government, Department of Health and Ageing, Commonwealth of Australia, Health Workforce Division, Canberra.

\section{REFERENCES}

1. Teusner DN, Chrisopoulos S, Brennan DS. Geographic distribution of the Australian dental labour force. 2003. Cat.no. DEN 168. Dental Statistics and research Canbera: AlHW; 37.

2. Australian Research Centre for Population Oral Health. Working papers of the ARCPOH/Australian Institute of Health and Welfare Dental Statistics and Research Unit workshop on the dental labour force. Adelaide, SA: ARCPOH/AIHW,2002. 
3. Sengupta TK, Murray RB, McDonell A, Murphy B, Underhill AD. Rural internships for final year students: clinical experience, education and workforce. Rural Rem Health 2008;8:827. http://www.rrh.org.au .

4. Wilson M, Cleland J. Evidence for the acceptability and academic success of an innovative remote and rural extended placement. Rural Rem Health 2008;8:960. http://www.rrh. org.au.

5. Wilkinson D, Laven G, Pratt N, Beilby J. Impact of undergraduate and postgraduate rural training, and medical school entry criteria on rural practice among Australian general practitioners: national study of 2414 doctors. Med Edu J 2003;37:809-814.

6. Playford D, Larson A, Wheatland B. Going country: rural student placement factors associated with future rural employment in nursing and allied health. Aus $J$ Rural Health 2006;14:14-16.

7. Daniels ZM, Vanleit BJ, Sanders ML, Rhyne RL. Factors in recruiting and retaining health professionals for rural practice. J Rural Health 2007;23:62-71.

8. Dunbabin J, Levitt L. Rural origin and rural medical exposure: their impact on the rural and remote medical workforce. Rural Rem Health 2003;3:212.

9. Hsueh W, Wilkinson T, Bills J. What evidence-based undergraduate interventions promote rural health? NZMJ 2004;117:1117.

10. Laven G, Wilkinson D. Rural doctors and rural backgrounds: How strong is the evidence? A systematic review. Aus J Rural Health 2003;11:277-284

11. Rolfe IE, Pearson SA, O'Connell DL, Dickinson JA. Finding solutions to the rural doctor shortage: the roles of selection versus undergraduate medical education at Newcastle. Aus N Z J Med 1995;25:512-517.

12. Dalton LM, Routley GK, Peek KJ. Rural placements in Tasmania: do experimental placements and background influence undergraduate health science student's attitudes toward rural practice? Rural Rem Health 2008;8:962. http:// www.rrh.org.au.

13. Ranmuthugala G, Humphreys J, Solarsh B et al. Where is the evidence that rural exposure increases uptake of rural medical practice? Aus J Rural Health 2007;15:285-288.

14. Nunn J, Freeman R, Anderson E et al. Inequalities in access to education and healthcare Eur J Den Educ 2008;12:30-39.

15. Bazen JJ, Kruger E, K Dyson, Tennant M. An innovation in Australian dental education: rural, remote and Indigenous pre-graduation placements. Rural Rem Health 2007; 7:703.

16. Abuzar MA, Burrow MF, and Morgan M. Development of a rural outplacement programme for dental undergraduates: students' perceptions. Eur J Dent Educ 2009;13:233239.
17. Mascarenhas AK, Henshaw M. Infrastructure for a Community-Based Dental Education Program: Students and Clinics. J Dent Educ;74:17-24.

18. Richards L, Symon B, Burrow D, Chartier A, Misan G, Wilkinson D. Undergraduate student experience in dental service delivery in rural South Australia: An analysis of costs and benefits. Aust Dent J 2002;47;254-258.

19. Bailit HL. Organization and Management of CommunityBased Dental Education Progams: An Overview from the Dental Pipeline Program, J Dent Educ 2010;74:9-16.

20. Elkind A, Alinkhorn BS, Blinkhorn FA, Duxbury JT, Hull PS, Brunton P. Developing dental education in primary care: The student perspective. Br Dent J 2005;198:233-237.

21. Craddock HL. Outreach teaching - the Leeds experience: reflections after one year. Br Dent J 2008;204:319-324.

22. Johnson GE, Blinkhorn AS. Student opinions on a rural placement program in New South Wales, Australia. Rural Rem Health 2011;11:1703. 